Wesleyan University

From the SelectedWorks of Charles A. Sanislow, Ph.D.

April, 2004

Psychophysiological reactivity to traumatic and abandonment scripts in borderline personality and posttraumatic stress disorders: a preliminary report

Christian G. Schmahl

Bernet M. Elzinga

Ulrich W. Ebner

Timothy Simms

Charles A. Sanislow, et al. 


\title{
Psychophysiological reactivity to traumatic and abandonment scripts in borderline personality and posttraumatic stress disorders: a preliminary report
}

\author{
Christian G. Schmahl ${ }^{\mathrm{a} *}$, Bernet M. Elzinga ${ }^{\mathrm{b}}$, Ulrich W. Ebner ${ }^{\mathrm{a}}$, Timothy Simms ${ }^{\mathrm{c}}$, \\ Charles Sanislow $^{\mathrm{d}}$, Eric Vermetten ${ }^{\mathrm{e}}$, Thomas H. McGlashan ${ }^{\mathrm{d}}$, J. Douglas Bremner ${ }^{\mathrm{f}}$ \\ ${ }^{a}$ Department of Psychosomatic Medicine, Central Institute of Mental Health, J 5, D-68159 Mannheim, Germany \\ ${ }^{\mathrm{b}}$ Department of Clinical Psychology, University of Leiden, Leiden, The Netherlands \\ ${ }^{\mathrm{c}}$ Department of Psychiatry and Psychotherapy, University of Freiburg Medical School, Freiburg, Germany \\ ${ }^{\mathrm{d} Y a l e}$ Psychiatric Research, Yale University School of Medicine, New Haven, CT, USA \\ ${ }^{\mathrm{e}}$ Department of Psychiatry, University Medical Center/Central Military Hospital, Utrecht, The Netherlands \\ ${ }^{\mathrm{f}}$ Departments of Psychiatry and Behavioral Sciences and Radiology, and Center for Positron Emission Tomography, \\ Emory University School of Medicine, Atlanta, GA, and Atlanta VAMC, Decatur, GA, USA
}

Received 11 October 2002; received in revised form 30 December 2003; accepted 15 January 2004

\begin{abstract}
Borderline personality disorder (BPD) is a highly prevalent and disabling condition linked to early stressors including traumatic abuse and abandonment. While much work has addressed traumatic events in childhood, little is known about the biological sequelae of BPD including how this disorder may be differentiated from other stressrelated disorders such as posttraumatic stress disorder (PTSD). The purpose of this study was to investigate psychophysiological effects of different types of stressful reminders in BPD and in PTSD. Psychophysiological measures including heart rate, skin conductance responses, systolic and diastolic blood pressure in response to standardized neutral scripts, and personalized scripts of traumatic and abandonment situations were compared among subjects with BPD, PTSD and controls, all with a reported history of sexual and/or physical abuse before age 18 . Significant script by diagnosis interactions are found for skin conductance and systolic blood pressure. No significant effects were found for diastolic blood pressure or heart rate. In the PTSD group the greatest systolic blood pressure responses were to traumatic scripts, whereas patients with BPD showed a tendency towards greater skin conductance responses to abandonment scripts. Our findings reveal only partially different psychophysiological responses to traumatic and abandonment scripts in PTSD and BPD. A divergence in pathophysiology in these two disorders is suggested that may be linked to childhood trauma. However, this interpretation must be tested in a larger population. (c) 2004 Elsevier Ireland Ltd. All rights reserved.
\end{abstract}

Keywords: Borderline personality disorder; Posttraumatic stress disorder; Psychophysiology; Stress response; Early abuse; Abandonment

\footnotetext{
*Corresponding author. Tel.: +49-621-1703-171; fax: +49-621-1703-172.

E-mail address: schmahl@zi-mannheim.de (C.G. Schmahl).
} 


\section{Introduction}

Borderline personality disorder (BPD) is a highly prevalent condition affecting approximately $1.3 \%$ of the population (Torgersen et al., 2001). Compared with the influence of developmental events, little is known about the biology of BPD. Chief among stressors thought to play a pivotal role in the development of BPD is childhood abuse (Zanarini, 1997). Childhood abuse experiences, most often assessed in prior studies, include physical and sexual abuse, such as being physically injured, raped, or assaulted (Links et al., 1988; Herman et al., 1989; Zanarini et al., 1989; Ogata et al., 1990; Westen et al., 1990). However, adverse events in the range of emotional abuse or neglect also play a significant role in the development of psychopathology. One adverse event that is clinically significant in BPD is abandonment during the course of development, where the child was left alone or isolated for long periods of time (Gunderson, 1996). Possibly due to traumatic experiences or abuse associated with being left alone, the BPD individual develops abandonment fears (Benjamin, 1996). Based on this, DSM-IV (American Psychiatric Association, 2000) includes 'frantic efforts to avoid real or imagined abandonment' as one of the nine diagnostic criteria for BPD. On a neurofunctional level, memories of abandonment could be shown to be responsible for prefrontal cortex dysregulation in patients with BPD (Schmahl et al., 2003).

BPD has recently been suggested to be part of the stress-related psychiatric disorder spectrum (Bremner, 1999). According to that model, traumatic stress can alter structural and functional aspects of the brain and lead to the development of a range of psychiatric disorders that share in common a relationship to stress. These include depression, posttraumatic stress disorder (PTSD), dissociative disorders, and BPD. A high rate of diagnostic co-occurrence of BPD with PTSD has been documented; about half of BPD patients have comorbid PTSD (McGlashan et al., 2000).

Psychophysiological variables, including heart rate, systolic and diastolic blood pressure, and skin conductance, reflect in part activity of the peripheral sympathetic nervous system. Measurement of these psychophysiological variables in conjunction with stimulation of PTSD-specific symptoms using techniques such as hearing a traumatic script is a method that has been used extensively to study conditioned emotional responding and sympathetic correlates of exposure to traumatic reminders in PTSD (Blanchard and Buckley, 1999). Challenge studies of this sort that have examined PTSD subjects have yielded relatively consistent results. In studies that have compared Vietnam combat veterans with and without PTSD, subjects that heard 'personalized' scripts of their traumatic experiences have demonstrated an increase in heart rate (Pitman et al., 1987, 1990; for review: Prins et al., 1995). Shin et al. (1999) found higher heart rate and blood pressure responses for subjects with childhood sexual abuse-related PTSD as compared with controls when subjects were exposed to traumatic scripts. Challenge studies using traumatic scripts have the advantage that the scripts directly stimulate the symptoms, which are most characteristic of the disorder, namely, remembrance of the traumatic event in PTSD patients.

The first study of physiological correlates of emotional stress in BPD was conducted by Herpertz et al. (1999). They examined 24 female patients with BPD and compared them with 27 normal control subjects. Participants were shown a set of standardized (i.e. not personalized) photographic slides with pleasant, neutral, or unpleasant emotional valence. Physiological reactions to the slides were measured by heart rate, skin conductance, and startle response. The borderline patients did not produce higher levels of startle amplitude, and startle potentiation in BPD subjects did not differ from control subjects during presentation of unpleasant slides. Furthermore, neither skin conductance nor heart rate responses differed between patients and controls. One possibility for these findings is that the stimuli in the study of Herpertz et al. were not salient reminders for trauma in BPD subjects.

In the present study, we sought to extend the challenge method of traumatic scripts in PTSD by developing a method using stimuli most salient for BPD. We considered that feelings of real or imagined abandonment are a core element of the BPD presentation. Because PTSD and BPD often share 
in common a history of childhood trauma, we decided to compare psychophysiological correlates of abandonment and traumatic scripts among subjects reporting a history of abuse with BPD, PTSD, and no psychiatric disorder. We hypothesized that subjects with PTSD would show a greater psychophysiological reaction to a traumatic script than to an interpersonally-based script describing an abandonment situation, whereas BPD subjects would demonstrate a larger reaction to the abandonment script than to the traumatic script.

\section{Methods}

\subsection{Subjects}

Forty women, all with a history of sexual and/ or physical abuse, were recruited by advertisements in newspapers and flyers. Ages ranged from 20 to 57 years. Subjects with organic mental disorders, a history of head trauma or cerebral infectious disease, lifetime psychotic disorder, and use of benzodiazepines were excluded from participation in the study. Subjects were not actively abusing substances or alcohol in the past 3 months. After complete explanation of the study procedures and before subjects entered the study, written informed consent was obtained. Subjects were paid for participation in the study. The study has been carried out in accordance with the Declaration of Helsinki.

\subsection{Assessment}

History of traumatic childhood events was assessed using the Early Trauma Inventory-selfreport-version (ETI). Psychometric properties of the clinician-administered ETI have been published (Bremner et al., 2000). The ETI is an interview that assesses physical, emotional, and sexual abuse. For each item of the ETI, frequency of trauma, perpetrator of the trauma by developmental stage, onset and termination of trauma, and impact on the individual are assessed. Dissociative traits were assessed with the Dissociative Experience Scale (DES; Bernstein and Putnam, 1986). Axis I diagnoses were assessed by a trained psychiatrist (C.G.S) and psychologist (B.M.E.) using the
Structured Clinical Interview for DSM-IV Axis I disorders (SCID; First et al., 1995). Assessment of current PTSD was augmented by the ClinicianAdministered PTSD Scale for DSM-IV, Current and Lifetime Version (CAPS; Blake et al., 1997). Axis II diagnoses were assessed using the Diagnostic Interview for DSM-IV Personality Disorders (DIPD; Zanarini et al., 1996).

\subsection{Study groups}

All subjects fulfilling diagnostic criteria for BPD as assessed by the DIPD-IV were classed with the BPD group, regardless of PTSD intensity as indicated by their CAPS score. For participants without BPD, a CAPS cut-off score of 50 or higher was used to classify subjects in the PTSD group, and the remainder comprised the abuse control (AC) group. All individuals in the PTSD group met full DSM criteria for current PTSD. Mean CAPS total scores were 78.4 (S.D. = 12.2) for the PTSD group, 20.5 (13.8) for the AC group and 44.9 (26.3) for the BPD group. The stringent guideline of two or fewer BPD criteria as determined by the DIPD-IV was required for subjects to be included in the PTSD or AC groups.

In all, 16 subjects were assigned to the AC, 14 to the PTSD, and 10 to the BPD group. The mean age was not different between groups. In the AC group, 14 subjects were Caucasian, one African American and one Hispanic. In the PTSD group, eight subjects were Caucasian, three African American, two Hispanic, and one Asian. In the BPD group, nine subjects were Caucasian and one African American. Of the 16 AC subjects, five were taking psychotropic medication during their participation in the study, as were five of 14 PTSD subjects and eight of 10 BPD subjects. ETI scores did not significantly differ among the three groups with mean scores of 78.7 for the AC, 77.2 for the PTSD, and 73.8 for the BPD group. Mean DES scores differed among the groups with highest means in the BPD group (BPD: 29.1; PTSD 15.2; AC: 10.7). For complete psychometric and demographic data, see Table 1.

Most subjects in all three groups had a lifetime diagnosis of major depressive disorder. During the time of the study, however, no subject in the AC 
Table 1

ANOVA results for baseline psychometric and demographic variables

\begin{tabular}{|c|c|c|c|c|c|c|}
\hline & \multirow{2}{*}{$\begin{array}{l}\text { AC } \\
\text { Mean (S.D.) }\end{array}$} & \multirow{2}{*}{$\begin{array}{l}\text { PTSD } \\
\text { Mean (S.D.) }\end{array}$} & \multirow{2}{*}{$\begin{array}{l}\text { BPD } \\
\text { Mean (S.D.) }\end{array}$} & \multicolumn{2}{|c|}{ Diagnosis $* * *$} & \multirow[t]{2}{*}{$t$-test } \\
\hline & & & & $F$ & $P$ & \\
\hline Age & $36.6(11.0)$ & $36.2(10.5)$ & $30.2(12.2)$ & 1.26 & 0.296 & - \\
\hline Height & $65.1(2.3)$ & $64.6(2.7)$ & $64.2(3.0)$ & 0.370 & 0.694 & - \\
\hline ETI & 70.85 (39.71) & $77.23(22.61)$ & $73.80(32.23)$ & 0.127 & 0.881 & - \\
\hline DES & $10.71(11.58)$ & $14.78(16.53)$ & $29.05(29.05)$ & 5.739 & $0.008 * *$ & $\begin{array}{l}\mathrm{BPD}>\mathrm{AC}^{* *} \\
\mathrm{BPD}>\mathrm{PTSD}^{*}\end{array}$ \\
\hline Weight & $176.8(53.8)$ & $154.0(40.7)$ & $170.2(60.41)$ & 0.780 & 0.466 & - \\
\hline BPDSS & $1.125(1.668)$ & $5.769(9.444)$ & $4.700(9.346)$ & 1.624 & 0.211 & - \\
\hline CADSS & $1.000(1.673)$ & $6.385(9.023)$ & $3.5(6.570)$ & 2.660 & 0.084 & - \\
\hline CAPS & $20.50(13.78)$ & $77.61(12.33)$ & $44.90(26.31)$ & 38.649 & $0.000 * *$ & $\begin{array}{l}\mathrm{PTSD}>\mathrm{AC}^{* *} \\
\mathrm{PTSD}>\mathrm{BPD}^{* *} \\
\mathrm{BPD}>\mathrm{AC}^{* *}\end{array}$ \\
\hline PTSDSS & $16.75(2.64)$ & $21.54(10.34)$ & $22.10(12.20)$ & 1.589 & 0.218 & \\
\hline SUDSS & $17.44(17.62)$ & $22.31(19.11)$ & $29.00(31.87)$ & 0.816 & 0.450 & \\
\hline Anxiety & $0.375(0.619)$ & $1.154(0.987)$ & $0.800(0.919)$ & 3.158 & 0.054 & \\
\hline Fear & $0.063(0.250)$ & $0.385(0.870)$ & $0.600(1.350)$ & 1.290 & 0.288 & \\
\hline
\end{tabular}

$* P<0.05 ; * * P<0.001 ; \mathrm{ETI}=$ Early Trauma Inventory; DES $=$ Dissociative Experience Scale; BPDSS = Borderline Personality Disorder Symptom Scale; CADSS = Clinician-Administered Dissociative States Scale; CAPS = Clinician-Administered PTSD Scale; PTSDSS $=$ PTSD Symptom Scale; SUDSS $=$ Subjective Units of Distress Scale. $* * *$ d.f. $=2,36$.

group, three subjects in the PTSD group, and four in the BPD group met criteria for a current diagnosis of major depressive episode. Five out of 10 BPD subjects met criteria for current PTSD. Further current comorbid diagnoses were Panic Disorder with Agoraphobia (BPD: $n=3$ ), Panic Disorder without Agoraphobia (AC: 1; PTSD: 1; BPD: 2), Social Phobia (AC: 1; PTSD: 2; BPD: 2), Generalized Anxiety Disorder (PTSD: 2; BPD: 1), Obsessive-Compulsive Disorder (BPD: 1), and Bulimia Nervosa (BPD: 1).

\subsection{Procedure}

Several days prior to the challenge day, one of the interviewers assisted the subject in preparing two personalized scripts using an established method (Pitman et al., 1987; Bremner et al., 1999). The participant was first asked to describe a severe childhood sexual or physical abuse event in writing on a script preparation form. The participant's response was reviewed and a script approximately 1 min in length was composed by the interviewer portraying the experience in the first person, present tense (traumatic script). Next, the participant was asked to describe a situation of abandonment she had experienced during her lifetime, again using a script preparation form and composing a script of about $1 \mathrm{~min}$ in length, describing the event in the first person, present tense (abandonment script).

For the challenge, subjects were placed in a quiet room in a reclining chair with two investigators present. After a resting period of $20 \mathrm{~min}$, a standardized neutral story $1 \mathrm{~min}$ in length was read to the subjects by a female investigator. Two minutes after the end of the script, subjective ratings were collected, including the 17-item PTSD Symptom Scale (PTSDSS; Southwick et al., 1993), the Borderline Personality Disorder Symptom Scale, a 10-item Instrument for the Assessment of Borderline State Symptoms (BPDSS; Schmahl et al., in preparation), the ClinicianAdministered Dissociative States Scale, a reliable and valid 27-item Scale for the Measurement of Current Dissociative States (CADSS; Bremner et al., 1998), the Subjective Units of Distress Scale (SUDS; a visual analog scale scored from 0 to 100 for the assessment of current subjective level of distress), and two scales for the assessment of fear and anxiety scored from 0 to 4 (Southwick et al., 1993). Ten and $20 \mathrm{~min}$ after the neutral story, 
this procedure was repeated, once with the traumatic script, and once with the abandonment script. To control for order effects, the presentation of the two personalized scripts was randomized.

Heart rate was continuously assessed using a heart rate monitor (Polar Electro Inc., Woodbury, $\mathrm{NY}$ ) with a sampling rate of $0.2 \mathrm{~Hz}$. Skin conductance was measured by finger electrodes on the second and third fingers of the right hand and online registration (sampling rate: $32 \mathrm{~Hz}$; BioGraph, Thought Technology Ltd., Montreal, Canada). Blood pressure was assessed using an automatically inflatable blood pressure cuff at two time points, $1 \mathrm{~min}$ before reading of the script and $3 \mathrm{~min}$ after the beginning of the script. In addition to these measures, saliva samples for the assessment of cortisol levels were obtained at different time points during the study (data not presented here).

\subsection{Analyses}

For the analysis of heart rate and skin conductance, two time periods were evaluated, each 1 min in length. Baseline values were taken from the period between 2 and $1 \mathrm{~min}$ before the reading of the scripts. Script values were assessed during the 1-min reading period. In each period, six consecutive values for heart rate were assessed with 10-s intervals between values, and the mean of these six values was calculated. Two tonic parameters of electrodermal activity are especially useful to measure long-lasting stimuli: skin conductance level (SCL) and number of skin conductance (SC) fluctuations. We chose number of SC fluctuations because this parameter is a better electrodermal measure for emotional activation than SCL (Boucsein, 1992; Kilpatrick, 1972).

To reduce variance associated with unusually large responses, square root transformations were performed on physiological response scores prior to statistical analysis. For each psychophysiological variable, a change score was calculated by subtracting the transformed baseline values from the transformed values after the script period (blood pressure) or from the transformed values for the reading period (heart rate and number of SC fluctuations). We applied an analysis of variance (ANOVA) with diagnosis (BPD, PTSD, AC) as between-subject factor and type of script (neutral, trauma, abandonment) as within-subject factor. Since the three groups differed significantly in their CAPS values (see Table 1), we used the CAPS score as a covariate in all following analyses. Dependent variables were the change scores of the four parameters: heart rate, SC responses, systolic blood pressure, and diastolic blood pressure. We also analyzed psychometric variables (PTSDSS, BPDSS, CADSS, SUDSS, VAS fear and anxiety) at initial baseline (Table 1) and after each script (Table 2) using ANOVA with type of script as within-subject factor, diagnosis as between-subject-factor, and CAPS scores as the covariate.

To examine more closely the hypothesis of specificity of the scripts for the different groups, contrast analyses were used in those cases, where a significant group by script interaction was observed. We used the Greenhouse-Geisser-correction to correct for violations of the sphericity assumption in all ANOVAs.

\section{Results}

\subsection{Subjective ratings}

We found no significant script by diagnosis interactions for any of the subjective ratings. See Table 2 for full statistical details.

\subsection{Psychophysiology}

There were no significant script, diagnosis, or script by diagnosis effects for the baseline values of the psychophysiological variables. See Table 3 for full statistical details. Also, we found no significant interactions between diagnosis and type of script for heart rate and diastolic blood pressure.

\subsection{Systolic blood pressure}

Due to a technical problem, blood pressure could not be assessed in one subject in the PTSD group. Overall, we found a significant diagnosis by script interaction $(F=3.461, P=0.015)$. Contrast analyses revealed significantly higher levels of blood pressure in the PTSD group for the abandonment 
Table 2

ANOVA results for subjective ratings

\begin{tabular}{|c|c|c|c|c|c|c|c|c|c|c|}
\hline & \multirow[t]{2}{*}{ Diagnosis } & \multirow{2}{*}{$\begin{array}{l}\text { Abandonment } \\
\text { Mean (S.D.) }\end{array}$} & \multirow{2}{*}{$\begin{array}{l}\text { Neutral } \\
\text { Mean (S.D.) }\end{array}$} & \multirow{2}{*}{$\begin{array}{l}\text { Trauma } \\
\text { Mean (S.D.) }\end{array}$} & \multicolumn{2}{|c|}{ Diagnosis*** } & \multicolumn{2}{|c|}{ Script**** } & \multicolumn{2}{|c|}{ Interaction $* * * * *$} \\
\hline & & & & & $F$ & $P$ & $\bar{F}$ & $P$ & $\bar{F}$ & $P$ \\
\hline \multirow[t]{3}{*}{ BPDSS } & $\mathrm{AC}$ & $3.500(3.033)$ & $0.500(0.894)$ & $4.688(4.423)$ & 0.573 & 0.469 & 3.832 & $0.031 *$ & 0.873 & 0.476 \\
\hline & PTSD & $9.231(11.713)$ & $5.154(8.867)$ & $10.923(11.521)$ & & & & & & \\
\hline & BPD & $10.200(10.020)$ & $4.200(8.817)$ & $9.500(8.657)$ & & & & & & \\
\hline \multirow[t]{3}{*}{ PTSDSS } & $\mathrm{AC}$ & $25.824(9.876)$ & 15.529 (3.777) & $28.941(10.109)$ & 0.163 & 0.884 & 6.782 & $0.005^{* *}$ & 1.592 & 0.186 \\
\hline & PTSD & $33.615(14.914)$ & $21.077(11.608)$ & $39.077(15.851)$ & & & & & & \\
\hline & BPD & $29.800(12.700)$ & $21.200(12.865)$ & $30.000(10.853)$ & & & & & & \\
\hline \multirow[t]{3}{*}{ SUDSS } & $\mathrm{AC}$ & $34.588(26.484)$ & $17.059(16.111)$ & $37.353(27.393)$ & 1.191 & 0.316 & 5.450 & $0.007 * *$ & 0.386 & 0.809 \\
\hline & PTSD & $41.539(25.363)$ & $24.385(23.272)$ & $50.000(27.157)$ & & & & & & \\
\hline & BPD & $43.500(33.003)$ & $25.100(26.773)$ & $47.500(25.522)$ & & & & & & \\
\hline \multirow[t]{3}{*}{ Anxiety } & $\mathrm{AC}$ & $0.882(1.111)$ & $0.529(0.624)$ & $1.118(1.111)$ & 0.781 & 0.466 & 4.488 & $0.021^{*}$ & 1.849 & 0.143 \\
\hline & PTSD & $1.692(1.182)$ & $1.154(0.987)$ & $2.000(1.155)$ & & & & & & \\
\hline & BPD & $1.700(1.059)$ & $0.800(0.919)$ & $1.800(0.919)$ & & & & & & \\
\hline \multirow[t]{3}{*}{ Fear } & $\mathrm{AC}$ & $0.353(0.786)$ & $0.059(0.243)$ & $0.235(0.437)$ & 1.535 & 0.230 & 3.912 & $0.025^{*}$ & 1.551 & 0.199 \\
\hline & PTSD & $0.308(0.855)$ & $0.154(0.376)$ & $0.462(0.967)$ & & & & & & \\
\hline & BPD & $0.900(1.287)$ & $0.400(0.966)$ & $0.700(1.252)$ & & & & & & \\
\hline \multirow{3}{*}{ CADSS } & $\mathrm{AC}$ & $1.375(1.746)$ & $0.625(0.885)$ & $3.125(4.425)$ & 0.188 & 0.829 & 2.504 & 0.107 & 2.386 & 0.082 \\
\hline & PTSD & 9.385 (13.370) & $6.077(8.995)$ & 14.615 (18.577) & & & & & & \\
\hline & BPD & $7.800(14.597)$ & $4.200(8.791)$ & $5.900(4.886)$ & & & & & & \\
\hline
\end{tabular}

$* P<0.05 ; * * P<0.01 ;$ BPDSS $=$ Borderline Personality Disorder Symptom Scale; CADSS = Clinician-Administered Dissociative States Scale; PTSDSS $=$ PTSD Symptom Scale; SUDSS $=$ Subjective Units of Distress Scale. $* * *$ d.f. $=2,3 ; * * * *$ d.f. $=2,74 ; * * * *$ d.f. $=4,74$.

script compared with the neutral script, and for the trauma script compared with the neutral script. We also found significantly higher levels of blood pressure for the trauma script in the $\mathrm{AC}$ and the PTSD groups than in the BPD group. See Table 4 for full statistical details.

\subsection{Number of SC fluctuations}

Due to a technical problem, this parameter could not be assessed in two subjects in the BPD group and one in the PTSD group. There was a significant interaction between diagnosis and type of script for number of SC fluctuations $(F=3.437$,
$P=0.019)$. However, contrast analysis revealed no significant contrasts between the scripts in any of the groups, and also no significant contrasts between the diagnostic groups in any of the scripts. See Table 4 for full statistical details.

\section{Discussion}

This study examined the specificity of psychophysiological responses to personalized narratives of traumatic and abandonment events, and to a neutral script in subjects with BPD, PTSD, and those with no psychiatric diagnosis. Our hypothesis of a differential effect of traumatic and abandon-

Table 3

ANOVA results for baseline scores of physiological variables

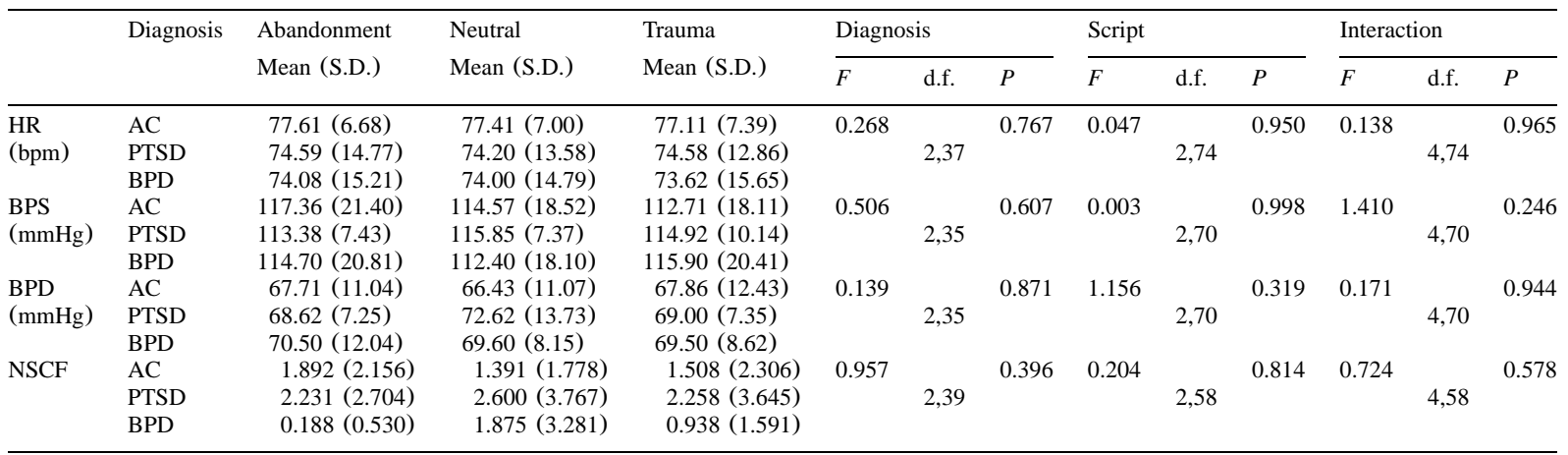

$* P<0.05 ; * * P<0.01 ; \mathrm{HR}=$ heart rate; $\mathrm{BPS}=$ systolic blood pressure; $\mathrm{BPD}=$ diastolic blood pressure; NSCF $=$ number of skin conductance fluctuations. 
Table 4

ANOVA results for change scores of physiological variables (values are square-root-transformed)

\begin{tabular}{|c|c|c|c|c|c|c|c|c|c|c|c|c|c|c|}
\hline & \multirow[t]{2}{*}{ Diagnosis } & \multirow{2}{*}{$\begin{array}{l}\text { Abandonment } \\
\text { Mean (S.D.) }\end{array}$} & \multirow{2}{*}{$\begin{array}{l}\text { Neutral } \\
\text { Mean (S.D.) }\end{array}$} & \multirow{2}{*}{$\begin{array}{l}\text { Trauma } \\
\text { Mean (S.D.) }\end{array}$} & \multicolumn{3}{|c|}{ Diagnosis } & \multicolumn{3}{|l|}{ Script } & \multicolumn{3}{|c|}{ Interaction } & \multirow[t]{2}{*}{ Contrasts } \\
\hline & & & & & $\bar{F}$ & d.f. & $P$ & $\bar{F}$ & d.f. & $P$ & $F$ & d.f. & $P$ & \\
\hline \multirow{2}{*}{$\begin{array}{l}\mathrm{HR} \\
(\mathrm{bpm})\end{array}$} & $\mathrm{AC}$ & $0.034(0.177)$ & $-0.007(0.159)$ & $0.013(0.254)$ & \multirow[t]{2}{*}{0.750} & & \multirow[t]{2}{*}{0.480} & \multirow[t]{2}{*}{1.686} & & \multirow[t]{2}{*}{0.201} & \multirow[t]{2}{*}{1.010} & & \multirow[t]{2}{*}{0.395} & \\
\hline & BPD & $0.037(0.337)$ & $-0.023(0.084)$ & $0.081(0.220)$ & & & & & & & & & & \\
\hline \multirow{3}{*}{$\begin{array}{l}\text { BPS } \\
(\mathrm{mmHg})\end{array}$} & $\mathrm{AC}$ & $0.113(0.379)$ & $-0.054(0.234)$ & $0.203(0.257)$ & \multirow[t]{3}{*}{0.764} & & \multirow[t]{3}{*}{0.474} & \multirow[t]{3}{*}{0.411} & & \multirow[t]{3}{*}{0.651} & \multirow[t]{3}{*}{3.461} & & \multirow[t]{3}{*}{$0.015^{*}$} & \multirow{9}{*}{$\begin{array}{l}\text { PTSD: } \\
\text { aband }>\text { neut* } \\
\text { traum }>\text { neut** } \\
\text { Trauma: } \\
\text { PTSD }>\text { BPD* } \\
\text { AC }>\text { BPD* }\end{array}$} \\
\hline & PTSD & $0.237(0.438)$ & $-0.208(0.583)$ & $0.584(0.404)$ & & 2,3 & & & 2,3 & & & 4,7 & & \\
\hline & BPD & $0.013(0.348)$ & $0.130(0.391)$ & $-0.071(0.354)$ & & & & & & & & & & \\
\hline BPD & $\mathrm{AC}$ & $-0.028(0.359)$ & $0.037(0.190)$ & $-0.006(0.362)$ & \multirow[t]{3}{*}{1.025} & & \multirow[t]{3}{*}{0.370} & \multirow[t]{3}{*}{0.568} & & \multirow[t]{3}{*}{0.568} & \multirow[t]{3}{*}{0.444} & & \multirow[t]{3}{*}{0.775} & \\
\hline \multirow[t]{2}{*}{$(\mathrm{mmHg})$} & PTSD & $0.189(0.354)$ & $-0.192(0.521)$ & $0.458(0.333)$ & & 2,35 & & & 2,70 & & & 4,70 & & \\
\hline & $\mathrm{BPD}$ & $0.156(0.595)$ & $-0.019(0.329)$ & $0.075(0.305)$ & & & & & & & & & & \\
\hline \multirow[t]{3}{*}{ NSCF } & $\mathrm{AC}$ & $0.631(0.675)$ & $0.747(0.783)$ & $0.974(0.704)$ & \multirow[t]{3}{*}{0.064} & & \multirow[t]{3}{*}{0.938} & \multirow[t]{3}{*}{0.416} & & \multirow[t]{3}{*}{0.636} & 3.437 & & $0.019^{*}$ & \\
\hline & PTSD & $0.580(1.341)$ & $0.483(0.823)$ & 0.979 (1.269) & & 2,29 & & & 2,58 & & & 4,58 & & \\
\hline & BPD & $1.658(1.859)$ & $-0.096(0.0147)$ & $0.341(1.260)$ & & & & & & & & & & \\
\hline
\end{tabular}

$* P<0.05 ; * * P<0.001 ; \mathrm{HR}=$ heart rate; $\mathrm{BPS}=$ systolic blood pressure; $\mathrm{BPD}=$ diastolic blood pressure; NSCF $=$ number of skin conductance fluctuations. 
ment scripts in PTSD and BPD could not be confirmed. PTSD patients in this study exhibited greater increases in systolic blood pressure to traumatic scripts and abandonment scripts relative to neutral scripts, partially confirming the findings of Shin et al. (1999).

A number of studies (Pitman et al., 1987, 1990; Blanchard et al., 1982; McFall et al., 1990; Orr et al., 1993; Shin et al., 1999) have investigated psychophysiological reactivity to trauma-related scripts in patients with PTSD. In contrast to the present study, most former studies found more pronounced heart rate responses in PTSD. We were not able to replicate the findings of larger heart rate responses to traumatic reminders in patients with PTSD. Heart rate differences in response to trauma-related imagery were found in combat-related PTSD in male veterans (Pitman et al., 1987, 1990; Blanchard et al., 1982; McFall et al., 1990; Orr et al., 1993) and abuse-related PTSD in female patients (Shin et al., 1999; Carson et al., 2000; Orr et al., 1998).

BPD patients had a pattern of larger SC responses to the abandonment script as compared to the other two scripts; however, these differences did not reach a significant level. The fact that the differences in SC responses within the BPD group did not reach statistical significance may have partly been due to the limited sample size in that group $(n=8)$. However, the SC responses from our study cannot be compared directly to previous findings in PTSD since we used a different methodology (number of SC fluctuations). In addition to the small sample size of the BPD group, the lack of clear responses in heart rate and blood pressure to abandonment and trauma scripts in patients with BPD may also reflect a relative lack of physiological responsivity to stressful scripts. Psychophysiological responsivity to stressors in patients with BPD is part of a yet unresolved debate. From a clinical point of view, BPD patients were described to show affective hyperarousal in response to emotional stressors (Linehan, 1993). In a laboratory setting, however, hyperarousal in response to stressful stimuli has not been clearly demonstrated, either in the present study or in earlier investigations (Herpertz et al., 1999, 2001).
Some of the findings could also be explained by higher levels of dissociative traits in the BPD group, since this group had a significantly higher mean DES score than the other two groups. Dissociative symptoms with a lower awareness of the contents of the scripts during the measurement of psychophysiological parameters could influence autonomic reactivity. Measurements of dissociative states by use of the CADSS during the challenge procedure, however, did not reveal similar high values for the BPD group as for the PTSD group. The difference between dissociative traits and states in this study population remains unclear, and this suggests that a more complex process than acute dissociating is operating.

The fact that responses to traumatic and abandonment scripts were not different might be partly due to the fact that half of the patients in this group also fulfilled criteria for PTSD. Alternatively, skin conductance as well as psychological reactivity to both traumatic and abandonment scripts could support the idea that both types of stressors play a role in the development of BPD, and many times the two are linked. Most studies focused on physical and sexual abuse, and the ability to measure these constructs is well developed (Links et al., 1988; Herman et al., 1989; Zanarini et al., 1989; Ogata et al., 1990; Westen et al., 1990). Recently, however, other adverse experiences, including emotional abuse and neglect, have been studied, and there is some suggestion that these experiences may be equally detrimental to outcome (Bremner et al., 2000). Abandonment, as chosen in our study, represents one example for a situation of emotional neglect, particularly salient for the case of BPD. However, it may need to be better differentiated from abuse. For instance, several subjects portrayed instances of abandonment directly related to their abuse situation (e.g. failure to protect).

Several limitations should be considered in evaluating our findings. As already mentioned, half of the BPD subjects also fulfilled criteria for PTSD and this may have confounded the differences between the two groups. However, exclusion of comorbid PTSD would lead to a sample not representative for BPD with its high rate of traumatic experience. The small sample size of the 
BPD group precluded us from analyzing the subgroups of BPD patients with and without PTSD separately. However, none of the subjects in our PTSD group exhibited BPD. Our results also underscore the importance of completely assessing the presence of Axis I and Axis II disorders. About one third of the AC as well as the PTSD group and nearly all BPD subjects were taking psychotropic medication during the study. In our experience it is nearly impossible to recruit BPD patients without psychotropic medication, and doing so might bias selection of a less impaired study group. Antidepressants and neuroleptics certainly influence psychophysiological reactivity and might have contributed to overall lower responses in the BPD group. Finally, we made use of a standardized neutral script as opposed to the personalized scripts of traumatic and abandonment memories. Thus, intensity of personal memories could contribute to differences in responses between neutral and stressful scripts.

Even though BPD is one of the more widespread psychiatric disorders, to our knowledge this is the first study assessing psychophysiological reactivity of BPD patients to stressful reminders. Our clinical understanding of BPD as compared to PTSD suggests a divergence in pathophysiology. However, our results provide only modest support for this hypothesis and warrant follow-up tests using larger sample sizes.

\section{Acknowledgments}

This study was supported by NIMH R01 \#MH56120 and a VA Career Development Award to Dr Bremner. This work was further supported by NIH/NIMH K05 1654 (Dr McGlashan), and by the Borderline Personality Disorder Research Foundation (Drs Bremner, Elzinga, McGlashan, Sanislow, Schmahl, and Vermetten). Gratitude is also owed to Dr Mary Zanarini for training in the reliable use of the Diagnostic Interview for DSMIV Personality Disorders.

\section{References}

American Psychiatric Association, 2000. Diagnostic and Statistical Manual of Mental Disorders. 4th ed. American Psychiatric Association, Washington, DC.
Benjamin, L.S., 1996. Interpersonal Diagnosis and Treatment of Personality Disorders. 2nd ed. Guilford Press, New York.

Bernstein, E.M., Putnam, F.W., 1986. Development, reliability and validity of a dissociation scale. Journal of Nervous and Mental Disease 174, 727-735.

Blake, D.D., Weathers, F.W., Nagy, L.M., Kaloupek, D.G., Charney, D.S., Keane, T.M., 1997. Clinician-Administered PTSD Scale for DSM-IV, Current and Lifetime Version. National Center for Posttraumatic Stress Disorder, Boston, MA and West Haven, CT.

Blanchard, E.B., Buckley, T.C., 1999. Psychophysiological assessment of posttraumatic stress disorder. In: Saigh, P.A., Bremner, J.D. (Eds.), Posttraumatic Stress Disorder: A Comprehensive Text. Allyn and Bacon, Boston, pp. 248-266.

Blanchard, E.B., Kolb, L.C., Pallmeyer, T.P., Gerardi, R.J., 1982. A psychophysiological study of post-traumatic stress disorder in Vietnam veterans. Psychiatry Quarterly 54, 220-229.

Boucsein, W., 1992. Electrodermal Activity. Plenum Press, New York.

Bremner, J.D., 1999. Acute and chronic responses to stress: where do we go from here? [Editorial]. American Journal of Psychiatry 156, 349-351.

Bremner, J.D., Krystal, J.H., Putnam, F., Southwick, S.M., Marmar, C., Charney, D.S., Mazure, C.M., 1998. Measurement of dissociative states with the Clinician Administered Dissociative States Scale (CADSS). Journal of Traumatic Stress 11, 125-136.

Bremner, J.D., Narayan, M., Staib, L.H., Southwick, S.M., McGlashan, T., Charney, D.S., 1999. Neural correlates of childhood sexual abuse in women with and without posttraumatic stress disorder. American Journal of Psychiatry 156, 1787-1795.

Bremner, J.D., Vermetten, E., Mazure, C.M., 2000. Development and preliminary psychometric properties of an instrument for the measurement of childhood trauma: the Early Trauma Inventory. Depression and Anxiety 12, 1-12.

Carson, M.A., Paulus, L.A., Lasko, N.B., Metzger, L.J., Wolfe, J., Orr, S.P., Pitman, R.K., 2000. Psychophysiologic assessment of posttraumatic stress disorder in Vietnam nurse veterans who witnessed injury or death. Journal of Consulting and Clinical Psychology 68, 890-897.

First, M.B., Spitzer, R.L., Gibbon, M., Williams, J.B.W., 1995. Structured Clinical Interview for Axis-I DSM-IV Disorders, Patient Edition (SCID-I/P). Biometrics Research Department, New York State Psychiatric Institute, New York.

Gunderson, J.G., 1996. The borderline patient's intolerance of aloneness. Insecure attachments and therapist availability. American Journal of Psychiatry 153, 752-758.

Herman, J.L., Perry, J.C., van der Kolk, B.A., 1989. Childhood trauma in borderline personality disorder. American Journal of Psychiatry 146, 490-495.

Herpertz, S.C., Kunert, H.J., Schwenger, U.B., Sass, H., 1999. Affective responsiveness in borderline personality disorder: a psychophysiological approach. American Journal of Psychiatry $156,1550-1556$. 
Herpertz, S.C., Werth, U., Lukas, G., Qunaibi, M., Schuerkens, A., Kunert, H.-J., Freese, R., Flesch, M., Mueller-Isberner, R., Osterheider, M., Sass, H., 2001. Emotion in criminal offenders with psychopathy and borderline personality disorder. Archives of General Psychiatry 58, 737-745.

Kilpatrick, D.G., 1972. Differential responsiveness of two electrodermal indices to psychological stress and performance of a complex cognitive task. Psychophysiology 9, 218-226.

Linehan, M.M., 1993. Cognitive Behavioral Treatment of Borderline Personality Disorder. Guilford Press, New York.

Links, P.S., Steiner, M., Offord, D.R., Eppel, A., 1988. Characteristics of borderline personality disorder: a Canadian study. Canadian Journal of Psychiatry 33, 336-340.

McFall, M.E., Murburg, M.M., Ko, G.N., Veith, R.C., 1990. Autonomic responses to stress in Vietnam combat veterans with posttraumatic stress disorder. Biological Psychiatry 27, 1165-1175.

McGlashan, T.H., Grilo, C.M., Skodol, A.E., Gunderson, J.G., Shea, M.T., Morey, L.C., Zanarini, M.C., Stout, R.L., 2000. The Collaborative Longitudinal Personality Disorders Study: baseline axis I/II and II/II diagnostic co-occurrence. Acta Psychiatrica Scandinavica 102, 256-264.

Ogata, S.N., Silk, K.R., Goodrich, S., Lohr, N.E., Westen, D., Hill, E.M., 1990. Childhood sexual and physical abuse in adult patients with borderline personality disorder. American Journal of Psychiatry 147, 1008-1013.

Orr, S.P., Pitman, R.K., Lasko, N.B., Herz, L.R., 1993. Psychophysiological assessment of posttraumatic stress disorder imagery in World War II veterans. Journal of Abnormal Psychology 102, 152-159.

Orr, S.P., Lasko, N.B., Metzger, L.J., Berry, N.J., Ahern, C.E., Pitman, R.K., 1998. Psychophysiologic assessment of women with posttraumatic stress disorder resulting from childhood sexual abuse. Journal of Consulting and Clinical Psychology 66, 906-913.

Pitman, R.K., Orr, S.P., Forgue, D.F., de Jong, J.B., Claiborn, J.M., 1987. Psychophysiologic assessment of posttraumatic stress disorder imagery in Vietnam combat veterans. Archives of General Psychiatry 44, 970-975.
Pitman, R., Orr, S., Forgue, D., Altman, B., de Jong, J., 1990. Psychophysiologic responses to combat imagery of Vietnam veterans with posttraumatic stress disorder vs. other anxiety disorders. Journal of Abnormal Psychology 99, 49-54.

Prins, A., Kaloupek, D.G., Keane, T.M., 1995. Psychophysiological evidence for autonomic arousal and startle in traumatized adult populations. In: Friedman, M.J., Charney, D.S., Deutch, A.Y. (Eds.), Neurobiological and Clinical Consequences of Stress: From Normal Adaptation to PTSD. Raven Press, New York.

Schmahl, C.G., Elzinga, B.M., Vermetten, E., Sanislow, C., McGlashan, T.H., Bremner, J.D., 2003. Neural correlates of memories of abandonment in women with and without borderline personality disorder. Biological Psychiatry 54, $142-151$.

Shin, L.M., McNally, R.J., Kosslyn, S.M., Thompson, W.L., Rauch, S.L., Alpert, N.M., Metzger, L.J., Lasko, N.B., Orr, S.P., Pitman, R.K., 1999. Regional cerebral blood flow during script-driven imagery in childhood sexual abuserelated PTSD: a PET investigation. American Journal of Psychiatry 156, 575-584.

Southwick, S.M., Krystal, J.H., Morgan, C.A., Johnson, D., Nagy, L.M., Nicolaou, A., Heninger, G.R., Charney, D.S., 1993. Abnormal noradrenergic function in posttraumatic stress disorder. Archives of General Psychiatry 50, 266-274.

Torgersen, S., Kringlen, E., Cramer, V., 2001. The prevalence of personality disorders in a community sample. Archives of General Psychiatry 58, 590-596.

Westen, D., Ludolph, P., Misle, B., Ruffins, S., Block, J., 1990. Physical and sexual abuse in adolescent girls with borderline personality disorder. American Journal of Orthopsychiatry 60, 55-66.

Zanarini, M.C., 1997. Role of Sexual Abuse in the Etiology of Borderline Personality Disorder. American Psychiatric Press, Washington, DC.

Zanarini, M.C., Gunderson, J.G., Marino, M.F., Schwartz, E.O., Frankenburg, F.R., 1989. Childhood experiences of borderline patients. Comprehensive Psychiatry 30, 18-25.

Zanarini, M.C., Frankenburg, F.R., Sickel, A.E., Yong, L., 1996. The Diagnostic Interview for DSM-IV Personality Disorders. McLean Hospital, Laboratory for the Study of Adult Development, Belmont, MA. 